\title{
Effect of Ulva Meal Supplement to Diet on the Lipid Metabolism of Red Sea Bream
}

\author{
Heisuke Nakagawa* and Shogoro Kasahara* \\ (Accepted April 10, 1986)
}

\begin{abstract}
A diet supplemented with $5 \%$ Ulva pertusa meal was fed to red sea bream Pagrus major. Growth was not affected, but hepatosomatic index and intraperitoneal fat body (IPF) ratio decreased slightly. Plasma nonesterified fatty acids (NEFA) and amino nitrogen changed significantly. The lipid levels of the dorsal muscle and liver were not affected apparently but the lipid class composition in the liver changed remarkably. Highly unsaturated fatty acids accumulated selectively in triglycerides of the Ulva meal fed fish. As to similarity of fatty acid composition, triglycerides of the liver and IPF were low between the two dietary groups.

Fish were subsequently starved for 21 days. Increase in plasma NEFA and decrease in amino nitrogen found in the experimental group suggested that the Ulva meal activated lipid mobilization and suppressed protein breakdown.

Starvation resulted in the utilization of highly unsaturated fatty acids in the Ulva meal fed fish, but fatty acids of the control group were uniformly consumed. Ulva meal was demonstrated to be capable of regulating lipid accumulation and mobilization in red sea bream.
\end{abstract}

Earlier studies showed that algae were not an effective source of protein to fish. Accordingly, we studied its merits on the physiological aspects such as improvement in body constituents, ${ }^{1-3}$ ) stress response, ${ }^{1,2,4)}$ and disease resistance. ${ }^{5}$ In addition, improvement of lipid metabolism was found in the ayu Plecogrossus altivelis, ${ }^{\left.{ }^{3}\right)}$ the black sea bream Acanthopagrus schlegeli, ${ }^{2)}$ and the yellowtail Seriola quinqueradiata. ${ }^{33}$ However, considerable differences occurred between various species.

Red sea bream is a high quality fish in Japan and the Inland Sea of Japan (Setonaikai) is wellknown for its production. Cultured red sea bream is comparatively less expensive than naturally caught fish. The improvement of the quality of cultured fish remains a problem. In the present study, red sea bream was fed on a diet supplemented with Ulva meal to find its effects on lipid accumulation and mobilization which influence the fish quality.

\section{Materials and Methods}

\section{Rearing condition}

Two hundred and thirty-six red sea bream Pagrus major each having $41 \mathrm{~g}$ body weight were divided into two groups and reared for 136 days in $0.5 \mathrm{~m}^{3}$ indoor tanks in the Fisheries Laboratory of the Hiroshima University.

\section{Diet}

Diet was prepared by the method of Furuichi and Yone, ${ }^{7)}$ as shown in Table 1. In the experimental group, diet was supplemented with dried and pulverized Ulva pertusa in the proportion of $5 \%$.

Table 1. Diet composition for red sea bream

\begin{tabular}{lcc}
\hline & Control & Experimental \\
\hline Vitamin-free Casein & 54 & 54 \\
Gelatin & 12 & 12 \\
Dextrin & 10 & 10 \\
Pollack liver oil & 9 & 9 \\
Cellulose & 3 & 3 \\
Elicitor (L-Asp-Na) & 1 & 1 \\
Amino acids*1 & 3 & 3 \\
Vitamins*2 & 3 & 3 \\
Minerals*3 & 5 & 5 \\
Ulva meal & 0 & 5 \\
Total & 100 & 105 \\
\hline Proximate composition & & \\
Moisture & $12.8 \%$ & $17.3 \%$ \\
Crude ash & $4.5 \%$ & $5.2 \%$ \\
Crude protein & $73.7 \%$ & $69.5 \%$ \\
Lipid & $9.0 \%$ & $8.0 \%$ \\
\hline$* 1$ L-Val 0.7, L-Arg.HCl 1.5, L-Try 0.2, L-Phe 0.6. \\
*2 Halver's vitamin mixture. \\
*a ICN Nutritional Biochemical Salt Miture No. 2. \\
\hline
\end{tabular}

* Faculty of Applied Biological Science, Hiroshima University, Fukuyama, Hiroshima 720, Japan (中川平介, 笠原正五郎: 広岛大学生物生産学部). 
Table 2. Effect of Ulva meal supplemented diet on growth and morphological measurements of red sea bream

\begin{tabular}{|c|c|c|c|c|c|c|c|c|}
\hline \multirow{2}{*}{ Group } & \multicolumn{2}{|c|}{ Body weight (g) } & \multirow{2}{*}{$\underset{(\%)}{F C E^{* 1}}$} & \multirow{2}{*}{ PER *2 } & \multirow{2}{*}{$\begin{array}{l}\text { Condition } \\
\text { factor }\end{array}$} & \multirow{2}{*}{$\begin{array}{c}\text { Viscero } \\
\text { somatic } \\
\text { index } \\
(\%)\end{array}$} & \multirow{2}{*}{$\begin{array}{c}\text { Hepato } \\
\text { somatic } \\
\text { index } \\
(\%)\end{array}$} & \multirow{2}{*}{$\begin{array}{c}\text { Intraperi- } \\
\text { toneal } \\
\text { fat ratio } \\
(\%)\end{array}$} \\
\hline & Initial & Final & & & & & & \\
\hline Control & 41.0 & 101 & 60.6 & 0.82 & 30.7 & 5.66 & 1.51 & 0.71 \\
\hline Experimental & 41.2 & 105 & 62.9 & 0.91 & 29.4 & 5.02 & 1.31 & 0.52 \\
\hline
\end{tabular}

Table 3. Blood properties of red sea bream

\begin{tabular}{|c|c|c|c|c|c|c|c|c|c|}
\hline \multirow[b]{2}{*}{ Group } & \multirow{2}{*}{$\begin{array}{c}\text { Hemato- } \\
\text { crit } \\
(\%)\end{array}$} & \multirow{2}{*}{$\begin{array}{c}\text { Hemo- } \\
\text { globin } \\
(\mathrm{g} / 100 \mathrm{~m} /)\end{array}$} & \multirow{2}{*}{$\begin{array}{c}\mathrm{RBC} \\
\left(10^{8} / \mathrm{mm}^{3}\right)\end{array}$} & \multicolumn{6}{|c|}{ Plasma } \\
\hline & & & & $\begin{array}{l}\text { Protein } \\
(\mathrm{g} / 100 \mathrm{~m} l)\end{array}$ & $\begin{array}{c}\text { Lipid } \\
(\mathrm{mg} / \\
100 \mathrm{~m} l)\end{array}$ & $\mathrm{TG} / \mathrm{PL}$ & $\begin{array}{l}\text { NEFA } \\
(\mu \mathrm{Eq} / l)\end{array}$ & $\begin{array}{l}\text { Amino-N } \\
(\mathrm{mmol} / \mathrm{l})\end{array}$ & $\begin{array}{c}\text { Sugar } \\
(\mathrm{mg} / \\
100 \mathrm{ml})\end{array}$ \\
\hline Control & 32.8 & 6.36 & 4.09 & 2.45 & 789 & 1.17 & 417 & 1.20 & 38.7 \\
\hline $\begin{array}{l}\text { Experi- } \\
\text { mental }\end{array}$ & 34.1 & 6.34 & 4.04 & 2.29 & 563 & 0.89 & $258 * 2$ & $1.54 * 1$ & 33.6 \\
\hline
\end{tabular}

Table 4. Proximate composition of dorsal muscle and liver of red sea bream

\begin{tabular}{llcccc}
\hline & Group & Moisture & Ash & Crude protein & Lipid \\
\hline \multirow{2}{*}{ Dorsal muscle } & Control & $77.0 \%$ & $1.6 \%$ & $20.4 \%$ & $1.0 \%$ \\
& Experimental & $77.4 \%$ & $1.5 \%$ & $20.3 \%$ & $0.8 \%$ \\
\hline \multirow{2}{*}{ Liver } & Control & $64.3 \%$ & & & $12.7 \%$ \\
& Experimental & $61.5 \%$ & & & $11.5 \%$ \\
\hline
\end{tabular}

\section{Blood Analysis}

More than 10 fish were used for the blood sampling. The blood was collected from the Cuvierian duct with a heparinized plastic cylinge. After hematological measurements, the plasma was individually submitted to analysis for protein (Biuret method), lipid (Sulfo-phospho-vanillin method), and amino nitrogen (Lorentz and Flatter's method $\left.{ }^{8}\right)$. Triglycerides, phospholipids, nonesterified fatty acids (NEFA), and glucose were measured by enzymatic assay.

\section{Biochemical Analysis}

The dorsal muscle, liver, and intraperitoneal fat body (IPF) were obtained from five fish and pooled samples were subjected to proximate composition and lipid analysis. Lipid was extracted with methanol-chloroform. Lipid class composition was measured by Iatroscan TH-10 (Iatron Co. Ltd.). Triglycerides were isolated by preparative thin-layer chromatograph (Kieselgel 60 HPTLC, Merck) and the fatty acids were con- verted into methyl esters with DMF-dimethylacetal. Analysis was performed by a Shimadzu GC-4A gas chromatograph at $210^{\circ} \mathrm{C}$, using a glass column packed with Unisol 3000 . Liver glycogen extracted by $30 \% \mathrm{KOH}$ was purified by $95 \%$ ethanol and $10 \%$ trichloroacetic acid. And the content was measured by anthron method.

\section{Starvation}

Once the feeding experiment was over, the fish were kept starved for 21 days. Water temperature during starvation ranged from 20.0 to $25.6^{\circ} \mathrm{C}$ (average $22.0^{\circ} \mathrm{C}$ ). Blood and biochemical parameters after the starvation were measured.

\section{Results}

\section{Lipid Accumulation}

Table 2 shows the effect of Ulva meal supplement on growth and morphological measurements. The Ulva did not disturb growth rate, feeding activity or feed conversion efficiency. 
Table 5. Liver glycogen content* of red sea bream

\begin{tabular}{lcc}
\hline Group & $\begin{array}{c}\text { Before } \\
\text { starvation }\end{array}$ & $\begin{array}{c}\text { After } \\
\text { starvation }\end{array}$ \\
\hline Control & $10.1 \pm 12.1 \mathrm{mg} / \mathrm{g}$ & $1.2 \pm 0.9 \mathrm{mg} / \mathrm{g}$ \\
Experimental & $15.0 \pm 19.1 \mathrm{mg} / \mathrm{g}$ & $2.2 \pm 2.9 \mathrm{mg} / \mathrm{g}$ \\
\hline * Mean and SD.
\end{tabular}

Protein efficiency ratio slightly increased by the Ulva meal. Morphological variations such as condition factor (body weight/body length ${ }^{\text {s) }}$ ), body height/body length ratio, body width/body length ratio, and body width/body height ratio were indistinctive between the two groups. The viscera, liver, and intraperitoneal fat (IPF) were slightly depressed by the Ulva meal, but were not significant.

Hematocrit value, bemoglobin, and erythrocyte number did not change by the Ulva meal. However, NEFA and amino nitrogen were significantly different (Table 3). Plasma lipid level was somewhat low in the experimental group. The Ulva meal did not influence the other parameters.

The proximate composition of the dorsal muscle showed little difference between both groups (Table 4). Liver glycogen content was somewhat high in the experimental group but the difference was not significant (Table 5). Low moisture and lipid in the liver of the experimental group might be compensated by high level of protein or glycogen.

Table 6 shows lipid class composition of the dorsal muscle, liver, and IPF. While the influence of the Ulva meal was not high on muscle constituents, liver was remarkably affected in the proportion of triglycerides, phospholipids, and free fatty acids. However, there were no differences in IPF which mainly consisted of triglycerides.

Fatty acid composition of the dietary lipid was analyzed in order to compare with the reserved lipids of fish (Table 7). The fatty acid composi-
Table 7. Fatty acid composition of dietary lipid

\begin{tabular}{crc}
\hline Fatty acid & Control & Experimental \\
\hline $16: 0$ & $11.9 \%$ & $12.3 \%$ \\
$18: 0$ & $2.0 \%$ & $2.0 \%$ \\
$20: 0$ & $1.9 \%$ & $2.0 \%$ \\
$16: 1$ & $10.9 \%$ & $10.8 \%$ \\
$18: 1$ & $17.3 \%$ & $17.2 \%$ \\
$20: 1$ & $15.6 \%$ & $15.2 \%$ \\
$16: 2$ & $1.3 \%$ & $1.3 \%$ \\
$16: 3$ & $2.1 \%$ & $2.1 \%$ \\
$18: 2$ & $1.5 \%$ & $1.8 \%$ \\
$18: 3$ & $0.5 \%$ & $0.8 \%$ \\
$20: 4$ & $0.5 \%$ & $0.5 \%$ \\
$20: 5$ & $22.8 \%$ & $22.3 \%$ \\
$22: 2$ & $0.6 \%$ & $0.6 \%$ \\
$22: 3$ & $0.5 \%$ & $0.5 \%$ \\
$22: 5$ & $1.6 \%$ & $1.6 \%$ \\
$22: 6$ & $9.0 \%$ & $8.9 \%$ \\
\hline
\end{tabular}

tion were not so different between both groups. The lipid reserves consisted mainly of triglycerides whose composition varied depending on dietary conditions. Table 8 shows fatty acid composition of the triglycerides in the dorsal muscle, liver, and IPF. In the control group, $C_{16}$ and $C_{18: 1}$ were dominant components. However, the experimental group had relatively highly unsaturated fatty acids such as $\mathrm{C}_{20: s}, \mathrm{C}_{22: 5}$, and $\mathrm{C}_{22: 6}$ compared to the control group. The dorsal muscle and IPF of the experimental group were characterized by lower level of medium-chain fatty acids and high level of long-chain fatty acids. The fatty acid composition of the control group seemed to be relatively similar to that of the dietary lipid. However, the fatty acids of liver and IPF of the Ulva fed fish were fairly differenciated from the dietary fatty acids.

\section{Lipid Mobilization}

Morphological measurements and proximate composition after starvation are shown in Table

Table 6. Lipid class composition of red sea bream

\begin{tabular}{|c|c|c|c|c|c|c|}
\hline \multirow{2}{*}{ Lipid class } & \multicolumn{2}{|c|}{ Dorsal muscle } & \multicolumn{2}{|c|}{ Liver } & \multicolumn{2}{|c|}{ Intraperitoneal fat } \\
\hline & Cont. & Expt1. & Cont. & Expt1. & Cont. & Exptl. \\
\hline $\begin{array}{l}\text { Sterol esters, } \\
\text { others }\end{array}$ & Tr. & Tr. & Tr. & $2.1 \%$ & & \\
\hline Triglycerides & $40.3 \%$ & $38.5 \%$ & $75.2 \%$ & $58.0 \%$ & $98.3 \%$ & $98.5 \%$ \\
\hline Fatty acids & $1.7 \%$ & Tr. & $5.4 \%$ & $13.4 \%$ & & \\
\hline Cholesterol & $4.3 \%$ & $4.3 \%$ & $1.9 \%$ & $2.2 \%$ & Tr. & Tr. \\
\hline Partial glycerides & $1.0 \%$ & Tr. & $2.3 \%$ & $2.6 \%$ & Tr. & Tr. \\
\hline Phospholipids & $52.7 \%$ & $57.2 \%$ & $15.2 \%$ & $21.9 \%$ & $1.7 \%$ & $1.5 \%$ \\
\hline
\end{tabular}


Table 8. Fatty acid composition of triglycerides in red sea bream

\begin{tabular}{|c|c|c|c|c|c|c|}
\hline \multirow{2}{*}{ Fatty acid } & \multicolumn{2}{|c|}{ Dorsal muscle } & \multicolumn{2}{|c|}{ Liver } & \multicolumn{2}{|c|}{ Intraperitoneal fat } \\
\hline & Control & Experimental & Control & Experimental & Control & Experimental \\
\hline $14: 0$ & & & & & $4.3 \%$ & $1.4 \%$ \\
\hline $16: 0$ & $11.9 \%$ & $7.0 \%$ & $23.9 \%$ & $6.6 \%$ & $20.2 \%$ & $5.3 \%$ \\
\hline $18: 0$ & $9.3 \%$ & $3.1 \%$ & & & $6.9 \%$ & $1.7 \%$ \\
\hline $20: 0$ & & & & & $0.8 \%$ & $2.2 \%$ \\
\hline $16: 1$ & & & & & $9.3 \%$ & $3.6 \%$ \\
\hline $18: 1$ & $47.8 \%$ & $25.6 \%$ & $44.5 \%$ & $14.8 \%$ & $35.0 \%$ & $12.0 \%$ \\
\hline $20: 1$ & $4.1 \%$ & $8.9 \%$ & $5.6 \%$ & $10.1 \%$ & $6.5 \%$ & $8.0 \%$ \\
\hline $22: 1$ & $2.1 \%$ & $16.2 \%$ & $1.8 \%$ & & & $12.4 \%$ \\
\hline $18: 2$ & $7.0 \%$ & $5.8 \%$ & & & $4.0 \%$ & $1.6 \%$ \\
\hline $20: 2$ & & & $3.4 \%$ & $6.2 \%$ & $1.0 \%$ & $2.4 \%$ \\
\hline $18: 3$ & & & & & $0.7 \%$ & \\
\hline $20: 4$ & $2.1 \%$ & $4.3 \%$ & $2.0 \%$ & $6.6 \%$ & & $2.0 \%$ \\
\hline $20: 5$ & $11.8 \%$ & $18.3 \%$ & $10.2 \%$ & $21.1 \%$ & $6.4 \%$ & $18.1 \%$ \\
\hline $22: 5$ & $1.9 \%$ & $4.8 \%$ & $4.2 \%$ & $20.7 \%$ & $1.2 \%$ & $6.3 \%$ \\
\hline $22: 6$ & $2.0 \%$ & $6.0 \%$ & $4.4 \%$ & $13.9 \%$ & $2.2 \%$ & $23.0 \%$ \\
\hline
\end{tabular}

Table 9. Morphological measurements and proximate composition of red sea bream after starvation

\begin{tabular}{|c|c|c|c|c|c|c|}
\hline & & & \multicolumn{2}{|c|}{ Control } & \multicolumn{2}{|c|}{ Experimental } \\
\hline \multicolumn{3}{|c|}{ Body weight } & $105 \mathrm{~g}$ & $(95.5 \%)$ & $101 \mathrm{~g}$ & $(91.0 \%)$ \\
\hline \multicolumn{3}{|c|}{ Condition factor } & 29.1 & $\left(94.8 \%{ }^{\# 1}\right)$ & 28.9 & $(98.3 \%)$ \\
\hline \multicolumn{3}{|c|}{ Viscerosomatic index } & $4.05 \%$ & $\left(71.6 \% \%^{\#^{3}}\right)$ & $4.60 \% * 1$ & $(91.6 \%)$ \\
\hline \multicolumn{3}{|c|}{ Hepatosomatic index } & $0.80 \%$ & $\left(53.0 \% \%^{* 2}\right)$ & $0.96 \% * 1$ & $\left(73.3 \% \%^{\# 1}\right)$ \\
\hline \multicolumn{3}{|c|}{ Intraperitoneal fat ratio } & $0.33 \%$ & $(46.5 \%$ & $0.31 \%$ & $(59.6 \%)$ \\
\hline \multirow{4}{*}{$\begin{array}{l}\text { Proximate } \\
\text { composition }\end{array}$} & Dorsal & Moisture & $78.3 \%$ & $(102 \%)$ & $76.9 \%$ & $(99.4 \%)$ \\
\hline & muscle & Ash & $1.8 \%$ & $(113 \%)$ & $1.8 \%$ & $(120 \%)$ \\
\hline & & Crude protein & $19.6 \%$ & $(96.1 \%)$ & $20.9 \%$ & $(103 \%)$ \\
\hline & & Lipid & $0.3 \%$ & $(30.0 \%)$ & $0.3 \%$ & $(37.5 \%)$ \\
\hline \multirow[t]{2}{*}{ " } & Liver & Moisture & $75.4 \%$ & $(117 \%)$ & $70.4 \%$ & $(114 \%)$ \\
\hline & & Lipid & $5.8 \%$ & $(45.7 \%)$ & $5.3 \%$ & $(46.1 \%)$ \\
\hline
\end{tabular}

Parentheses indicate percentage when the value before starvation was 100 .

*1 Significantly different from control group $(p<0.05)$.

$\$ 1, \$ 2, \$ 8$ Significantly different from the value before stravation (respectively $p<0.001, p<0.01, p<0.05$ ).

9. Body weight loss was slightly higher in the experimental group, because the loss in the control group was compensated by high water intake. While condition factor, viscera, liver, and IPF decreased significantly by starvation in the control group, only decrease in the experimental group was found in liver weight.

Starvation changed the proximate composition (Table 9). In both groups, lipid level decreased in the dorsal muscle and liver, but moisture and protein remained unchanged in the dorsal muscle. The increase of the liver moisture seemed to accompany the decrease of lipid. Liver glycogen content markedly decreased in both groups (Table 5) but the rate of loss has a trend to be slow in the experimental group.
Several marked differences appeared in plasmological parameter after starvation (Table 10). Plasma lipid and triglycerides/phospholipids ratio decreased significantly in both groups. However, NEFA, amino nitrogen, and sugar changed differently in the two groups. NEFA level decreased in the control group, but increased in the experimental group. Decrease of amino nitrogen was remarkable in the experimental group compared to the control group. Sugar level remained unchanged in the control group but the increase was observed largely in the experimental group.

Lipid class composition (Table 11) in the dorsal muscle and IPF did not change by starvation. However, starvation resulted in a loss of liver triglycerides and a relative increase of phospholipids 
Table 10. Blood properties of red sea bream after starvation

\begin{tabular}{|c|c|c|c|c|}
\hline \multirow[b]{2}{*}{ Hematocrit } & \multicolumn{2}{|l|}{ Control } & \multicolumn{2}{|c|}{ Experimental } \\
\hline & $36.7 \%$ & $(93.6 \%)$ & $31.9 \%$ & $(93.5 \%)$ \\
\hline Hemoglobin & $5.74 \mathrm{~g} / 100 \mathrm{ml}$ & $(90.3 \%)$ & $5.85 \mathrm{~g} / 100 \mathrm{ml}$ & $(90.5 \%)$ \\
\hline Red blood cell & $3.86 \times 10^{8} / \mathrm{mm}^{3}$ & $(94.4 \%)$ & $39.0 \times 10^{8} / \mathrm{mm}^{8}$ & $(96.5 \%)$ \\
\hline Plasma protein & $2.61 \mathrm{~g} / 100 \mathrm{~m} l$ & $(107 \%)$ & $2.68 \mathrm{~g} / 100 \mathrm{ml}$ & $\left(117 \% \%^{\# 2}\right)$ \\
\hline Plasma lipid & $323 \mathrm{mg} / 100 \mathrm{~m} l$ & $\left(40.9 \% \%^{\sharp 2}\right)$ & $336 \mathrm{mg} / 100 \mathrm{ml}$ & $\left(59.7 \% \%^{* 1}\right)$ \\
\hline TG/PL ratio & 0.18 & $\left(15.7 \% \%^{\sharp 3}\right)$ & 0.23 & $\left(25.4 \% \%^{* 2}\right)$ \\
\hline NEFA & $338 \mu \mathrm{Eq} / l$ & $(81.1 \%)$ & $469 \mu \mathrm{Eq} / l$ & $(182 \%)$ \\
\hline Amino- $\mathbf{N}$ & $0.99 \mathrm{mmol} / \mathrm{l}$ & $(82.5 \%)$ & $0.87 \mathrm{mmol} / \mathrm{l}$ & $\left(56.5 \% \%^{* 3}\right)$ \\
\hline Sugar & $41.5 \mathrm{mg} / 100 \mathrm{~m} l$ & $(107 \%)$ & $90.6 \mathrm{mg} / 100 \mathrm{~m} l$ & $\left(270 \% \%^{3}\right)$ \\
\hline
\end{tabular}

Parentheses indicate percentage when the value before starvation was 100 .

Significantly different from the value before starvation (respectively $p<0.05, p<0.01, p<0.001$ ).

Table 11. Lipid class composition of red sea bream after starvation

\begin{tabular}{|c|c|c|c|c|c|c|}
\hline \multirow{2}{*}{ Lipid class } & \multicolumn{2}{|c|}{ Dorsal muscle } & \multicolumn{2}{|c|}{ Liver } & \multicolumn{2}{|c|}{ Intraperitoneal fat } \\
\hline & Cont. & Exptl. & Cont. & Exptl. & Cont. & Exptl. \\
\hline Sterol esters, others & Tr. & Tr. & Tr. & $0.6 \%$ & & \\
\hline Triglycerides & $38.9 \%$ & $39.2 \%$ & $31.4 \%$ & $41.9 \%$ & $97.4 \%$ & $99.4 \%$ \\
\hline Fatty acids & Tr. & Tr. & $6.3 \%$ & $12.6 \%$ & & \\
\hline Cholesterol & $4.5 \%$ & $5.7 \%$ & $9.5 \%$ & $6.7 \%$ & Tr. & Tr. \\
\hline Partial glycerides & Tr. & Tr. & $1.5 \%$ & $2.1 \%$ & $\mathrm{Tr}$ & $\mathrm{Tr}$. \\
\hline Phospholipids & $56.6 \%$ & $55.1 \%$ & $51.3 \%$ & $36.1 \%$ & $2.6 \%$ & $0.6 \%$ \\
\hline
\end{tabular}

Table 12. Fatty acid composition of triglycerides in red sea bream after starvation

\begin{tabular}{|c|c|c|c|c|c|c|}
\hline \multirow{2}{*}{ Fatty acid } & \multicolumn{2}{|c|}{ Dorsal muscle } & \multicolumn{2}{|c|}{ Liver } & \multicolumn{2}{|c|}{ Intraperitoneal fat } \\
\hline & Control & Experimental & Control & Experimental & Control & Experimental \\
\hline $14: 0$ & & & & $2.7 \%$ & $4.5 \%$ & $2.2 \%$ \\
\hline $16: 0$ & $17.4 \%$ & $29.4 \%$ & $34.6 \%$ & $24.4 \%$ & $18.7 \%$ & $9.9 \%$ \\
\hline $18: 0$ & $16.6 \%$ & $5.9 \%$ & & & $6.6 \%$ & $2.8 \%$ \\
\hline $20: 0$ & & & & & $0.6 \%$ & $1.7 \%$ \\
\hline $16: 1$ & & & & v & $8.6 \%$ & $6.0 \%$ \\
\hline $18: 1$ & $37.5 \%$ & $35.2 \%$ & $46.2 \%$ & $60.3 \%$ & $35.0 \%$ & $19.6 \%$ \\
\hline $20: 1$ & $7.7 \%$ & $6.7 \%$ & $6.4 \%$ & $5.7 \%$ & $8.8 \%$ & $8.3 \%$ \\
\hline $22: 1$ & $1.2 \%$ & $5.0 \%$ & & & & $8.0 \%$ \\
\hline $16: 2$ & & & & & $0.5 \%$ & \\
\hline $18: 2$ & $10.4 \%$ & $7.0 \%$ & & & $3.3 \%$ & $2.2 \%$ \\
\hline $20: 2$ & & & $1.8 \%$ & $2.6 \%$ & $1.2 \%$ & $2.2 \%$ \\
\hline $20: 4$ & $1.0 \%$ & $1.7 \%$ & $0.6 \%$ & $0.6 \%$ & & $4.0 \%$ \\
\hline $20: 5$ & $6.7 \%$ & $9.1 \%$ & $3.9 \%$ & $2.8 \%$ & $8.0 \%$ & $13.7 \%$ \\
\hline $22: 5$ & $0.7 \%$ & & $1.3 \%$ & & $1.2 \%$ & $5.9 \%$ \\
\hline $22: 6$ & $0.8 \%$ & & $5.2 \%$ & $1.0 \%$ & $1.8 \%$ & $13.5 \%$ \\
\hline
\end{tabular}

occurred. Liver free fatty acids were maintained at a high level in the experimental group. Thus, the changes in the liver were not drastic in the experimental group.

Fatty acid composition after starvation is presented in Table 12. The control group equally consumed fatty acids of the lipid reserves, and fatty acid composition was extremely similar between before and after starvation. The other hand, the experimental group consumed specifically highly unsaturated fatty acids which accumulated through the Ulva meal. The change was intensive in the liver of the experimental group and fatty acid composition was extremely different from that before starvation. 


\section{Discussion}

Cultured fish is generally considered to be fatty and poor in taste because of overfeeding. The accumulation of the lipid reserves which are less utilized might cause some physiological disorders. Algae, as feed supplement, was found to be effective for improvement of physiological condition of cultured fish. The red sea bream is believed to be carnivorous, but Ulva pertusa was frequently found in the digestive organs of juveniles during intermediate culture. The feeding habit is likely connected with some physiological merits.

Chlorellawextract feeding to ayu could depress the lipid reserves. ${ }^{1)}$. Algae meal supplement to diet increased muscle lipid level in black sea bream and yellowtail. ${ }^{2,3)}$ However, the muscle of the red sea bream did not show any changes in proximate composition when fed with Ulva extract. ${ }^{9}$ The constant nature of muscle lipid level was in contrast to that of the black sea bream and the other fishes previously observed. High glycogen and low triglycerides in the liver of the experimental group indicated suppression of lipid accumulation and activation of glycogenesis. The effect on muscle lipid level by algae feeding varied from species to species. The plasma constituents relating to lipid metabolism had been observed to change in earlier studies also. ${ }^{1-3,10)}$

Body lipid is usually related to dietary lipid. ${ }^{11}$ Although similar fatty acids were fed, fatty acid composition of triglycerides were different between two groups. Therefore, as far as the Ulva fed fish, it was unlikely that fatty acids were primarily derived from the dietary lipid. Fatty acid composition of the control group was similar to that of wild red sea bream. ${ }^{12}$ The fatty acid composition was not always regulated by dietary lipid alone, but rearing condition or certain physiologically active substance might also have contributed to it.

Fish must efficiently utilize the energy reserves to survive prolonged starvation under natural conditions. Severe starvation causes an increase in water content of the muscle and lowering of the muscle lipid reserves. The liver lipid and glycogen are almost completely consumed. In natural conditions the lipid reserves may be preferentially mobilized in order to minimize body weight loss. The low body weight loss observed in the control group during starvation was compensated by moisture intake. The decrease was more severe in the liver and IPF of the control group. In the experimental group, the muscle protein was mostly retained and initially the lipid reserves were consumed. The liver triglycerides seemed to mobilize when feed intake ceased. Therefore, the Ulva meal activated the initial breakdown of the lipid reserves and suppresion of breakdown of protein. The levels of plasma amino nitrogen and NEFA might reflect the changes in metabolism.

Selective consumption of fatty acid during starvation was described by many authors. ${ }^{13-20}$ ) The fatty acids such as $C_{18: 1}$, and $C_{18: 2}$ were preferentially consumed in the European eel,19) trout, ${ }^{14)}$ carp, ${ }^{15)}$ and yellowtail, ${ }^{18)}$ while polyunsaturated fatty acids were retained. However, somewhat opposite results have been reported in tilapia, ${ }^{17)}$ Japanese eel, ${ }^{18)}$ and trout ${ }^{19,20)}$ Accute stress conditions caused high consumption of specific polyenoic acids, according to Saddler et al., ${ }^{21}$ and Hayashi and Takagi. ${ }^{22}$ In this experiment, the Ulva meal activated and mobilized highly unsaturated fatty acids from the lipid reserves. The mode of mobilization of fatty acids was different in the two groups. It was noteworthy that the selectivity of fatty acids in red sea bream was markedly different from that of black sea bream*. In Ulva meal fed black sea bream, fatty acid composition did not change even after wintering. Thus, the selectivity of fatty acid might be variable depending on species and energy requirements. Deposition of unaccessive fatty acids would cause physiological disorder, as reported in the fish lacking in essential fatty acid. ${ }^{11)}$

Although the effective substance and mechanism by which the algae causes the changes are not known, there are several possible explanations. Algae supplement to fish diet would enhance physiological activities and accordingly lipid metabolism is likely to improve.

\section{Acknowledgements}

We are pleased to acknowledge the help of the following people: Mr. K. Sasada and Mr. K. Kamiyoshi (Fisheries Laboratory of Hiroshima University) for rearing of fish, Mr. K. Satoh and Mr. S. Ino-ue for technical assistance, and Mr. C. Yashima (Riken Vitamin Co. Ltd) for the generous gift of feed oil.

We are much indebted to Dr. M. M. Pratap for assistance in preparing the manuscript.

* Unpublished data. 
This work was partly supported by a Grant-in Aid from the Ministry of Education, Science, and Culture.

\section{References}

1) H. Nakagawa, S., Kasahara, E. Uno, T. Minami, and K. Akira: Aquiculture, 30, 192-201 (1983).

2) H. Nakagawa, S. Kasahara, T. Sugiyama, and I. Wada: Aquiculture, 32, 20-27 (1984).

3) H. Nakagawa, H. Kumai, M. Nakamura, and S. Kasahara: Bull. Japan. Soc. Sci. Fish., 51, 279286 (1985).

4) H. Nakagawa, H. Kumai, M. Nakamura, and $S$. Kasahara: Aquiculture, 30, 76-83 (1982).

5) H. Nakagawa, S. Kasahara, E. Uno, T. Minami, and K. Akira: Aquiculture, 29, 109-116 (1981).

6) H. Nakagawa, S. Kasahara, A. Tsujimura, and K. Akira: Bull. Japan. Soc. Sci. Fish., 50, 665-671 (1984).

7) M. Furuichi and Y. Yone: Bull. Japan. Soc. Sci. Fish., 46, 225-229 (1980).

8) K. Lorentz and B. Flatter: Clin. Chem., 20, 1553-1555 (1974).

9) H. Nakagawa, S. Kasahara, and H. Nishio: $J$. Fac. Appl. Biol. Sci. Hiroshima Univ., 23, 85-93 (1984).
10) H. Nakagawa, Y. Inazuka, S. Yamasaki, H. Hirata, and S. Kasahara: Aquiculture, 30, 67-75 (1982).

11) T. Watanabe: Comp. Biochem. Physiol, 73B, 3-15 (1982).

12) T. Ohshima, S. Wada, and C. Koizumi: Bull. Japan. Soc. Sci. Fish., 49, 1405-1409 (1983).

13) H. G. Dave, M.-J. J. Johanson-Sjöbeck, A. Larsson, K. Lewander, and V. Lidman: Comp. Biochem. Physiol., 53B, 509-515 (1976).

14) B. Jezierska, J. R. Hazel, and S. D. Gerking: $J$. Fish Biol., 21, 681-692 (1982).

15) H. Murata and T. Higashi: Bull. Japan. Soc. Sci. Fish., 46, 1333-1338 (1980).

16) I. Kamoi, S. Matsumoto, and T. Obara: Nogakushuhoh, 24, 50-54 (1979).

17) S. Satoh, T. Takeuchi, and T. Watanabe: Bull. Japan. Soc. Sci. Fish., 50, 79-84 (1984).

18) H. Higashi, K. Terada, S. Takeda, and T. Koyama: Vitamins, 50, 265-273 (1976).

19) A. J. Castledine and J. T. Buckley: J. Nutr., 110, 675-685 (1980).

20) C. Leger: Aquaculture, 25, 195-206 (1981).

21) J. B. Saddler, K. V. Koshi, and R. D. Cardwell: Lipid, 7, 90-95 (1972).

22) K. Hayashi and T. Takagi: Bull. Japan. Soc. Sci. Fish., 43, 1189-1194 (1977). 